\title{
Marketing Healthy Diets: The Impact of Health Consciousness on Chinese Consumers' Food Choices
}

\author{
Zhen Huang ${ }^{1}$, Yi-Dan Zhu ${ }^{2}{ }^{-}$, Jia Deng ${ }^{3}$ and Cheng-Lu Wang ${ }^{4, *(1)}$ \\ 1 School of Economics \& Management, Gannan Normal University, Ganzhou 341003, China; \\ 1100009@gnnu.edu.cn \\ 2 School of Educational Science, Gannan Normal University, Ganzhou 341003, China; 1200613006@gnnu.edu.cn \\ 3 School of Foreign Languages, Gannan Normal University, Ganzhou 341003, China; dengjia9483@163.com \\ 4 Department of Marketing, College of Business, University of New Haven, West Haven, CT 06516, USA \\ * Correspondence: cwang@newhaven.edu
}

Citation: Huang, Z.; Zhu, Y.-D.; Deng, J.; Wang, C.-L. Marketing Healthy Diets: The Impact of Health Consciousness on Chinese Consumers' Food Choices. Sustainability 2022, 14, 2059. https:// doi.org/10.3390/su14042059

Academic Editor: Richard James Volpe

Received: 8 November 2021

Accepted: 28 January 2022

Published: 11 February 2022

Publisher's Note: MDPI stays neutral with regard to jurisdictional claims in published maps and institutional affiliations.

Copyright: (C) 2022 by the authors. Licensee MDPI, Basel, Switzerland. This article is an open access article distributed under the terms and conditions of the Creative Commons Attribution (CC BY) license (https:// creativecommons.org/licenses/by/ $4.0 /)$.

\begin{abstract}
Dietary choices, as the types and amounts of foods that individuals consume, are a major determinant of human health and environmental sustainability. From a marketing perspective, it becomes imperative to identify and understand the factors that motivate consumers to adopt a sustainable diet and purchase healthy food. This research is an attempt to contribute to the literature by revealing the major driving forces leading to healthy food consumption and identifying its underlying mechanism. Based on a survey of the diets and lifestyles of 307 Chinese consumers in several cities of the Jiangxi and Guangdong provinces, our empirical results indicate that consumer health consciousness is a major predictor of the intention to purchase healthy products. Such a relationship is explained by the psychological benefits associated with the consumption experience and the perceived naturalness of the product. Moreover, a high perceived nutritional value will enhance the mediation influences of the psychological benefit and the perceived naturalness on purchase intention while a low perceived nutritional value tends to negate such an impact.
\end{abstract}

Keywords: sustainable diet; health consciousness; perceived psychological benefit; perceived naturalness; perceived nutritional level; marketing strategy

\section{Introduction}

Dietary choices have become a critical factor in global sustainability in terms of the UN's Sustainable Development Goals and the Paris Climate Agreement [1]. Sustainable eating is about choosing foods that are healthful to our environment and our bodies [2]. As the foods associated with improved health generally have low negative environmental impacts, a dietary transition toward greater consumption of healthier foods would generally improve environmental sustainability [1]. According to the Food and Agriculture Organization of the United Nations [3], a sustainable diet refers to "a diet with low environmental impacts, which contributes to food and nutrition security and to healthy life for present and future generations. A sustainable food system is protective and respectful of biodiversity and ecosystems, culturally acceptable, accessible, economically fair and affordable, nutritionally adequate, safe and healthy, while optimizing natural and human resources". The growth of functional agriculture represents the trend of the production of agricultural products with health improvement functions through bio-trophic enhancement technology or other biological engineering [4]. Functional agriculture changes agriculture from an "eating industry" to a "health industry", which is beneficial to the sustainable development of agriculture.

While the importance of eating a healthy diet and its impact on healthy consumer lifestyles and environmental sustainability has been recognized, the factors that facilitate consumer choice and the purchase of healthy food have not been well studied in the literature. There is a growing interest in developing functional foods that contribute to 
the maintenance and improvement of human health. In Japan, for instance, the Consumer Affairs Agency launched a Food with Function Claims (FFC) system, which evaluates scientific evidence on agricultural and marine health foods, describing the functional properties that warrant health claims to promote informed use by consumers [5]. Recently, the Chinese government has promoted the production and consumption of selenium-rich food as a functional food to improve the health of residents. Selenium is a trace element, or nutrient, that the body needs to stay healthy, and it plays a role in reducing the risks of diseases including cancer while protecting the body from infection [6]. China is one of the 40 countries designated as low in selenium by the World Health Organization [7]; in fact, $72 \%$ of the population is selenium deficient, and over 70 million residents are affected [8]. From a marketing perspective and consumer's point of view, it is important to identify key factors that influence consumers' purchase intentions and information sharing regarding healthy food [9]. To fill such a void, this study investigates the underlying mechanisms that explain healthy food consumption, taking the choice of selenium-rich vegetables as a case in point. We propose that consumer health consciousness influences the intention to purchase selenium-rich vegetables. Meanwhile, we contend that the relationship between health consciousness and the choice of a healthy diet is explained by psychological benefits and the perceived naturalness of the healthy food. We further suggest that the perceived nutritional value will moderate the impact of perceived psychological benefits and perceived naturalness on the intention to purchase healthy food.

The paper is organized as follows: We first develop a conceptualization of the research framework with hypotheses. We then report the results of an empirical survey of Chinese consumers in several cities. Finally, we present the conceptual contribution to the research literature and strategic implications to help marketers, consumers, food corporations, and policy makers arrive at better decisions.

\section{Conceptual Background and Research Hypothesis}

\subsection{Health Consciousness and the Purchase Intention of Healthy Food}

Health consciousness refers to the psychological inclination that motivates consumers to take healthy actions $[10,11]$. With the increase in life expectancy and income levels, health concerns are increasing along with the health boom [12]. Consumer awareness of healthy eating habits and healthy lifestyles continues to increase, and consumers are beginning to view the healthiness of food as one of the most important attributes and are buying more products that are positively associated with their health [13]. Health-conscious consumers care about their health, and they strive to enhance and maintain their health status by engaging in healthy behaviors, such as consuming healthy foods [14]. Research has shown that health consciousness can promote preventive care [10], positive attitudes toward organic foods [15], and the intention to purchase health-related products [16]. On the other hand, individuals who are less health conscious tend to have less motivation to engage in behaviors that help maintain health status [11] and therefore are more likely to choose unhealthy foods [17]. Consequently, the pursuit of health is positively associated with the willingness to purchase healthy functional foods [18]. Therefore, the following research hypothesis is proposed.

Hypothesis 1 (H1). Health consciousness enhances the intention to purchase healthy food.

\subsection{The Mediating Role of Perceived Psychological Benefits}

The consumption affect plays an important role in the shopping journey, in purchase decision-making, and in consumption experiences [19]. The goal of an individual's consumption behavior is not only to obtain specific products or services, but also to experience and enjoy the whole consumption process $[20,21]$, and positive emotions such as pleasure and stress relief are frequently associated with a healthy lifestyle and food consumption [22]. Consumers with strong health consciousness tend to appreciate the value of selenium-rich vegetables and other functional agricultural products, leading to a pleasant and relaxed 
mood as well as to the rewarding experiences associated with consumption [23]. Satisfaction from perceived psychological benefits thus will directly stimulate consumers' engagement and shopping enthusiasm [24]. The more positive the consumers' emotions are, the more they will pay attention to the advantages of the product, which in turn enhances their attitudes toward the product and their behavioral intention [25].

With the fast growth of the economy and the increasing life span, the need of food acquisition for contemporary consumers has been shifted from satisfying the basic functional need for maintenance of homeostasis to pursuing higher level needs for enjoyment, relaxation, and other emotional satisfactions in food choice. As health consciousness determines the quality of attributes that consumers consider important in their food choices [26], such choices will lead to their emotional responses and mood status. A positive mood evoked by a positive experience with healthy food brings psychological benefits such as ease of stress, comfort, and life satisfaction [27], which eventually lead to stronger intentions to purchase healthy food. Therefore, we propose the following mediation hypotheses:

Hypothesis 2 (H2). Health consciousness positively influences the psychological benefits of healthy food.

Hypothesis 3 (H3). The psychological benefits associated with healthy food enhances purchase intention.

Hypothesis 4 (H4). The positive influence of health consciousness on the intention to purchase healthy food is mediated by the psychological benefits.

\subsection{The Mediating Role of Perceive Naturalness}

Consumer food choices have an important impact on health as well as the environment via food production and consumption. However, a sustainable diet and healthy food may not always be consistent in consumers' perceptions. To promote sustainable food consumption, it is crucial to understand how consumers perceive the environmental friendliness and healthiness of food products and how they evaluate environmental friendliness and healthiness in general [28]. Indeed, a consumer's preference for a diet often reflects diverse needs which influence an individual's choice between healthy and tasty. Although healthy food can be delicious as well, in many cases consumers may face the tradeoff between delicious junk food and dull healthy food. Research shows that a consumer's health concern is positively associated with their willingness to consume green produce [29] and with the natural content of food [30]. Empirical studies further revealed that perceptions of naturalness directly or indirectly influence consumers' attitudes and acceptance of food [31], because perceived naturalness is closely related to the environmental concerns and ethical judgement of consumers [32]. While some researchers have suggested that the production type (organic versus conventional) and scale (large versus small) influence perceived naturalness [33], consumers across different countries (e.g., USA, India, and China) differ in their perceptions of the naturalness of food [34]. Accordingly, in addition to the psychological benefits associated with healthy food consumption, we further anticipate that perceived naturalness also plays an important role in explaining the relationship between health consciousness and the choice of a healthy diet. Perceived naturalness refers to a heuristic attribute used by consumers as an indicator of food quality $[35,36]$. Research has found that consumers generally prefer natural foods, which are believed to influence the health value of food [37]. Perceived naturalness in the form of natural labels is increasingly appearing in the market and is favored by consumers [38]. The reason behind the consumers' motivation to purchase healthy food is the natural content of the food. Consumer health consciousness increases the attention of consumers to the naturalness of the food [39]. Thus, the stronger the health consciousness of consumers, the more they pay attention to the natural diet and lifestyle, and the more likely they are to buy healthy foods. Therefore, we propose the following hypotheses:

Hypothesis 5 (H5). Health consciousness leads to perceptions of the naturalness of healthy food. 
Hypothesis 6 (H6). Perceived naturalness increases the intention to purchase healthy food.

Hypothesis 7 (H7). Perceived naturalness mediates the relationship between health consciousness and the intention to purchase healthy food.

\subsection{The Moderating Effect of Perceived Nutritional Value}

Nutrition is the material basis of human life and health [40]. After the satisfaction of food, people are increasingly concerned about balanced nutrition. The nutritional facts of food are considered as an attribute of a credit commodity, and if consumers have access to credible nutritional information, such a food may become a search commodity [41]. Empirical evidence has demonstrated that the use of nutritional information would significantly change consumers' food consumption patterns [42] and food choices [43]. In China, where this study was conducted, nutrition and health have become mainstream demands for food consumption $[44,45]$.

For health-conscious consumers, the higher nutritional value of the food will compensate for some loss of taste and thus will enhance their intention to purchase healthy food. For less health-conscious consumers, on the other hand, the nutritional value would be less likely to affect their food choice. When consumers associate psychological benefits with the food, high nutritional values will add complementary value that amplifies the positive impact on purchase intention, resulting in a positive moderated mediation effect. On the other hand, the perceived nutritional value would be a substitute for the perceived naturalness, and thus reduce the impact of perceived naturalness on purchase intention, leading to a negative moderated mediation effect [46]. Accordingly, the following moderated mediated hypotheses are proposed:

Hypothesis 8 (H8). Perceived nutritional value positively moderates the mediating influences of psychological benefits on the intention to purchase healthy food.

Hypothesis 9 (H9). Perceived nutritional value negatively moderates the mediating influences of perceived naturalness on the intention to purchase healthy food.

We summarize the above hypotheses in the Figure 1:

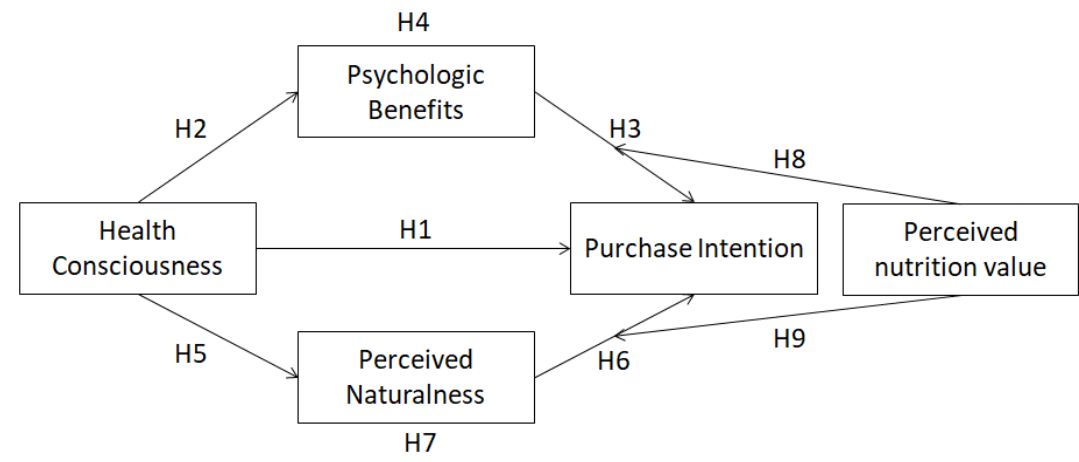

Figure 1. Research Model.

\section{Research Design and Methods}

\subsection{Product Selection}

Healthy food is a general concept and includes a variety of food categories. We selected selenium-rich vegetables as an indicator of healthy food for this study. Selenium is a trace element that is naturally present in many foods, added to others, and available as a dietary supplement. Selenium, which is nutritionally essential for humans, is a constituent of more than two dozen selenoproteins that play critical roles in reproduction, thyroid hormone metabolism, DNA synthesis, and protection from oxidative damage and infection. In the natural growth stage of crops, trace selenium is introduced into crops through various methods, and then high organic selenium-rich vegetables are produced 
through biotransformation [47]. Selenium in vegetables mainly exists in the form of organic selenium, which has high physiological activity, is easily absorbed by the human body, and can prevent and cure some human diseases. As the consumption of selenium-rich vegetables has been growing in China recently, it is appropriate to use it as an indicator of healthy food in this study.

\subsection{Measures}

Health consciousness was measured by a four-item scale adapted from Mai and Robert's study [48] (I reflect about my health a lot; I'm very self-conscious about my health; I'm generally attentive to my inner feelings about my health; and I am constantly examining my health).

Purchase intention was measured by a three-item scale (likely to buy, choice priority, and definitely will buy) adapted from Huang and Wang [49].

Psychological benefit was measured by a three-item scale (helps me cope with stress, helps me to cope with life, makes me feel good), adapted from Steptoe et al. [30].

Perceived naturalness was measured by three items adapted from Steptoe et al., (i.e., no additives, natural ingredients, no artificial ingredients).

Perceived nutrition value was also measured by three items adapted from Steptoe et al.: (contains a lot of vitamins and minerals, is nutritious and high in protein, is high in fiber and roughage).

All the above questionnaires were based on 5-point Likert scales, modified according to our study purpose, and showed adequate reliability and validity.

\subsection{Research Samples and Data Collection}

We collected data through both online and offline questionnaire surveys. The offline survey was conducted in several cities of the Jiangxi and Guangdong provinces, which are considered the major regions for producing and selling of selenium rich vegetables. The online survey data was collected through QuestionnaireStar (wjx.cn, accessed on 20 January 2021) - an online survey platform in China. We received 307 completed questionnaires (online $=47.6 \%$; male $=47.6$ ). The demographic information of the sample distribution is shown in Table 1:

Table 1. Sample Demographics $(\mathrm{N}=307)$.

\begin{tabular}{|c|c|c|c|c|c|}
\hline Gender & $\begin{array}{l}\text { Male } \\
\text { Female }\end{array}$ & $\begin{array}{l}146(47.6 \%) \\
161(52.4 \%)\end{array}$ & \multirow{4}{*}{$\begin{array}{l}\text { Year of } \\
\text { Birth }\end{array}$} & $\begin{array}{l}\text { Before 1970 } \\
1970-1979\end{array}$ & $\begin{array}{c}31(10.1 \%) \\
29(9.4 \%)\end{array}$ \\
\hline \multirow{3}{*}{ Education } & \multirow{3}{*}{$\begin{array}{c}\text { Elementary School or Less } \\
\text { Middle School } \\
\text { High School or } \\
\text { Technical school } \\
\text { Junior college } \\
\text { College or above }\end{array}$} & $\begin{array}{l}15(4.9 \%) \\
23(7.5 \%)\end{array}$ & & $\begin{array}{l}1980-1985 \\
1986-1990\end{array}$ & $\begin{array}{l}58(18.9 \%) \\
36(11.7 \%)\end{array}$ \\
\hline & & $29(9.4 \%)$ & & After 1990 & $104(33.9 \%)$ \\
\hline & & $\begin{array}{c}68(22.1 \%) \\
172(56.0 \%)\end{array}$ & & After 2000 & $49(16.0 \%)$ \\
\hline \multirow{5}{*}{$\begin{array}{l}\text { Monthly Income } \\
\text { (RMB) }\end{array}$} & 3000 or less & $115(37.5 \%)$ & \multirow{5}{*}{ Occupation } & Employees of government agencies & $33(10.7 \%)$ \\
\hline & $3001-5000$ & $82(26.7 \%)$ & & Enterprise employee & $105(34.2 \%)$ \\
\hline & $5001-8000$ & $47(15.3 \%)$ & & Farmer & $21(6.8 \%)$ \\
\hline & $8001-10,000$ & $17(5.5 \%)$ & & Self-employed or freelancers & $47(15.3 \%)$ \\
\hline & Above 10,001 & $46(15.0 \%)$ & & Others & $101(32.9 \%)$ \\
\hline
\end{tabular}

\section{Results and Analysis}

An initial check showed that the overall reliability coefficient (Cronbach's $\alpha$ ) of the questionnaire was 0.821 , indicating adequate overall reliability of the question. The KMO value $(0.821)$ and Bartlett's spherical test $(p<0.001)$ demonstrated a good overall structural validity. The correlation and descriptive statistics of the variables are shown in Table 2. 
Table 2. Descriptive statistics and correlations.

\begin{tabular}{ccccccccc}
\hline Variable & Cronbach's $\alpha$ & Mean & SD & $\mathbf{1}$ & $\mathbf{2}$ & $\mathbf{3}$ & $\mathbf{4}$ \\
\hline 1. Health consciousness & 0.78 & 3.80 & 0.95 & - & & & \\
2. Psychological benefits & 0.60 & 3.48 & 1.12 & $0.23^{* *}$ & - & & \\
3. Perceived naturalness & 0.72 & 3.72 & 0.98 & $0.42^{* *}$ & $0.34^{* *}$ & - & - \\
4. Perceived nutrition level & 0.61 & 3.72 & 0.93 & $0.34^{* *}$ & $0.41^{* *}$ & $0.47^{* *}$ & - \\
5. Purchase intention & 0.67 & 3.48 & 1.12 & $0.34^{* *}$ & $0.38^{* *}$ & $0.43^{* *}$ & $0.35^{* *}$ & - \\
\hline
\end{tabular}

Note(s): ${ }^{* *} p<0.01$.

Hypothesis testing was conducted using the structural equation model, with the biascorrected percentile bootstrap method (PROCESS Model 4, bootstrap samples 5000) to test the mediation and moderation hypotheses [50]. The results, as presented in Table 3 , showed that health consciousness significantly predicted purchase intention $(\beta=0.13, p<0.01)$, psychological benefits $(\beta=0.17, p<0.001)$, and perceived naturalness $(\beta=0.33, p<0.001)$. Thus, H1, H2, and H5 were supported. Next, the results showed that psychological benefits increased purchase intention $(\beta=0.31, p<0.001)$, and perceived naturalness significantly enhanced purchase intention $(\beta=0.27, p<0.001)$. Thus, both $\mathrm{H} 3$ and $\mathrm{H} 6$ were supported.

Table 3. Parallel mediating effects of relaxation and naturalness.

\begin{tabular}{|c|c|c|c|c|c|c|}
\hline \multirow{2}{*}{ Predictive Variables } & \multicolumn{2}{|c|}{$\begin{array}{c}\text { Model (1) } \\
\text { (Psychological Benefits) }\end{array}$} & \multicolumn{2}{|c|}{$\begin{array}{c}\text { Model (2) } \\
\text { (Perceived Naturalness) }\end{array}$} & \multicolumn{2}{|c|}{$\begin{array}{c}\text { Model (3) } \\
\text { (Purchase Intention) }\end{array}$} \\
\hline & $\beta$ & $\mathbf{t}$ & $\beta$ & $\mathbf{t}$ & $\beta$ & $\mathbf{t}$ \\
\hline Health consciousness & 0.17 & $4.19 * * *$ & 0.33 & $8.04^{* * *}$ & 0.13 & $2.94 * *$ \\
\hline Psychological Benefits & & & & & 0.31 & $5.20^{* * *}$ \\
\hline Perceived & & & & & 0.27 & $4.76^{* * *}$ \\
\hline $\begin{array}{c}\text { Naturalness } \\
R^{2}\end{array}$ & 0.05 & & 0.18 & & 0.28 & \\
\hline$F$ & 17.56 & & 64.68 & & 39.53 & \\
\hline
\end{tabular}

Note(s): ${ }^{* *} p<0.01 ; * * *<0.001$.

The mediation test results, as shown in Table 4, demonstrated that both psychological benefits and perceived naturalness partially mediated the effect between health awareness and purchase intention. The $95 \%$ bootstrap confidence interval for the mediated effect of psychological benefits and perceived naturalness did not include 0 . Thus, $\mathrm{H} 4$ and H7 were also supported.

Table 4. Parallel mediating effects and $95 \%$ CI for relaxation and naturalness.

\begin{tabular}{lccc}
\hline & Indirect Effect & \multicolumn{2}{c}{ 95\% CI } \\
\cline { 3 - 5 } Health Consciousness $\rightarrow$ Psychological Benefits $\rightarrow$ Purchase Intention & 0.05 & BootLLCI & BootULCI \\
\hline Health Consciousness $\rightarrow$ Perceived Naturalness $\rightarrow$ Purchase Intention & 0.09 & 0.02 & 0.10 \\
\hline
\end{tabular}

We further used PROCESS model 5 to test the moderated mediation hypotheses (H8 and H9). The results showed (see Table 5) that the interaction term between psychological benefits and perceived nutritional value was significant $(\beta=0.12, \mathrm{t}=2.06, p<0.05)$, indicating the mediating effect of psychotically benefits is moderated by perceived nutritional value. H8 was supported. Similarly, the significant interaction between perceived naturalness and perceived nutritional value $(\beta=-0.15, \mathrm{t}=-2.43, p<-0.05)$, supported H9. 
Table 5. Moderated Mediation Test.

\begin{tabular}{|c|c|c|}
\hline & \multicolumn{2}{|c|}{ Purchase Intention } \\
\hline & $\beta$ & $\mathbf{t}$ \\
\hline Health Consciousness & 0.17 & $2.97^{* *}$ \\
\hline Perceived Nutrition Value & 0.08 & 1.26 \\
\hline Health Consciousness $\times$ Perceived Nutrition Value & 0.13 & $2.02 *$ \\
\hline Psychological Benefits & 0.35 & $5.19^{* * *}$ \\
\hline Psychological Benefits $\times$ Perceived Nutrition & 0.12 & $2.06 *$ \\
\hline Perceived Naturalness & 0.21 & $3.37^{* * *}$ \\
\hline Perceived Naturalness $\times$ Perceived Nutrition Value & -0.15 & $-2.43^{*}$ \\
\hline$R^{2}$ & 0.31 & \\
\hline$F$ & 18.96 & \\
\hline
\end{tabular}

\section{Discussion and Conclusions}

Dietary choices, as the types and amounts of foods that individuals consume, are a major determinant of human health and environmental sustainability. Research evidence suggests the existence of synergy between sustainable diet and healthy food [28]. Such information would be beneficial to consumers in daily life and help food producers or marketers and policy makers make better decisions about food choices, food products, and food policies [1]. From a marketing perspective, it becomes imperative to identify and understand the factors that motivate consumers to adopt sustainable and healthy diets.

This research is an attempt to contribute to the literature by revealing the major driving forces leading to the purchase of healthy food and identifying its underlying mechanism (the mediators and moderator). In particular, the empirical results from our study of Chinese consumers indicate consumer health consciousness is a major predictor of the intention to purchase healthy products. Such a relationship is explained by the psychological benefits associated with the consumption experience and the perceived naturalness of the product. Moreover, this mediation mechanism is further moderated by perceived nutritional value, because a high perceived nutritional value will enhance the mediation influences of the psychological benefit and the perceived naturalness on purchase intention, while a low perceived nutritional value tends to negate such an impact.

\section{Strategic Impactions for Marketers and Policy Makers}

Even though a sustainable diet is recognized as economically fair and affordable and nutritionally adequate, safe, and healthy [51], there are still few countries that have adopted sustainable food principles into governmental nutrition recommendations [52]. Recently, under the Healthy China 2030 campaign, the Chinese government has promoted the integration of healthy food consumption into the healthy lifestyle. The dietary pattern of Chinese residents is undergoing transformation from quantity to quality, and then from quality to healthy. China is increasingly becoming the world's largest consumer market for nutritious and healthy food, and the demand for healthy food is growing rapidly. Functional and natural products occupy the main body of the healthy food market and drive the growth of the market and sustainable agriculture. To enhance consumers' preferences for functional agricultural products such as selenium-enriched vegetables, marketing strategies can be developed based on our research findings.

Given the key role of consumer health consciousness in influencing consumer choice and the intention to purchase healthy food, marketers and policy makers should focus on education programs through various channels to popularize health knowledge to consumers [53]. Key opinion leaders' (KOL's) endorsements or influencer marketing is effective in changing consumers' attitudes and diet choices in educational programs presented through various mass media and social media channels [54,55]. In particular, influencer marketing can help consumers better understand selenium nutrition, increase residents' awareness of health issues, and promote the concept of healthy eating for a 
healthy lifestyle. Such a KOL campaign with expert knowledge has also been found to be effective in enhancing consumer resistance to negative information regarding healthy food [56]. As our results showed that the knowledge of naturalness and nutritional value facilitates consumer decision-making. Advertising may attract consumers by emphasizing health-related information about positive nutritional content (e.g., "less fat and sugar") [57] as well as the positive outcomes of naturalness and the psychological benefits of a healthy diet. Meanwhile, making full use of the Internet media, a benign network atmosphere can have a positive effect on enhancing health awareness through electronic word-of-mouth [58]. The growth of social media makes content marketing a particularly effective tool for informing and persuading consumers through both cognitive and affective appeals [59]. For example, content marketing can be used to build health knowledge websites and social network sites to promote healthy diets, healthy lifestyles, and other related content [60].

As consumers' motivations can be both utilitarian and hedonic, their consumption choices could be both rational driven and affective driven, leading to selective attention to persuasive messages [61]. Therefore, in addition to providing health-related knowledge of healthy food, marketers can also highlight the psychological benefits of healthy food in the consumption experience [62]. Given that food consumption is experiential and highly associated with consumer emotions, salient psychological benefits associated with the consumption experience would increase consumer willingness to purchase healthy food [14]. Establishing interactive communication between marketers and consumers through social media marketing and livestreaming is an effective communication approach to engage consumers and enhance consumer purchase intention [63].

Meanwhile, in the contemporary digital age, building extensive brand fanbases or communities [64] or social networks of healthy food consumers would help connect healthy food users so that they may share experiences [65], which would build consumer-brand identity [66] and increase gratification and satisfaction [67]. Such brand communication is effective in enhancing consumer confidence in the authenticity of healthy products, which is important for consumer product adoption [68]. Marketers or brand managers may also create a selenium-rich visual image recognition system (VIS), e.g., cartoon images to enhance consumer interaction with fun and pleasurable experiences [69]. Through AR technology, users in online communities can grow vegetables in cloud games after obtaining a certain understanding of selenium-rich vegetables in the game [70]. According to the needs of the users and the operation of the game design, the platform could give users who complete certain tasks the corresponding selenium-rich agricultural products or leisure food. The platform could pay remuneration to farmers according to the trading volume of "rewards" and "recharges" carried out by users on the platform. Marketers can also create a "Selenium Tour" in line with the background setting of relaxed, healthy, and sustainable agriculture by using augmented reality, virtual reality, and other technologies to increase the sense of experience and interest of the game.

\section{Limitations and Future Research Directions}

First, we selected selenium-rich vegetables as an indicator of healthy food for this study because the consumption of selenium-rich vegetables has recently been growing in China (where this study was conducted). However, despite selenium's well-recognized health benefits, we must be cautious in drawing conclusions based on the use of seleniumrich vegetables to represent healthy food. Future studies are warranted to examine the issue with a variety of healthy food categories for making strategic recommendations that are beneficial to both human health and environmental substantiality.

Second, given the focus of this study is to investigate perceived benefits from seleniumrich vegetables as a choice of healthy food from the marketing perspective, it did not make an effort to evaluate and assess the impacts of such diet choice or consumption behaviors on environmental sustainability. While it is beyond the research focus and scope of this study, establishing or evaluating the sustainability index of the consumer diet would be an important next step in this line research. 
Third, we collected data from two specific regions that are considered the major regions for producing and selling selenium rich vegetables. A major caveat of our study context is the caution about generalizing the results from this study to other regions and other countries that have quite different environment factors such natural, economic, and cultural backgrounds. For instance, while selenium deficiency is very rare in North America [71], it is a major concern in over forty countries, including China. Therefore, the results from this study might not be generalizable to other countries without a selenium deficiency problem, and future empirical studies are needed to gain new insights.

Fourth, the Cronbach's $\alpha$ for some measurement scales was less than the normal cutoff point of 0.7 (above 0.6), although some experts suggest that Alpha Cronbach values in the range of $0.60-0.80$ are considered moderate, but acceptable [72]. It is desirable that future research improve the reliability of the measurement scales.

Author Contributions: Conceptualization, Z.H. and C.-L.W.; methodology, Z.H. and C.-L.W.; software, Z.H., J.D. and Y.-D.Z.; validation, Z.H., J.D. and Y.-D.Z.; formal analysis, Z.H.; investigation, Z.H., J.D. and Y.-D.Z.; resources, Z.H. and C.-L.W.; data curation, Z.H., J.D. and Y.-D.Z.; writing—original draft preparation, Z.H.; writing—review and editing, Z.H., Y.-D.Z. and C.-L.W.; visualization, Z.H., J.D. and Y.-D.Z.; supervision, C.-L.W.; project administration, C.-L.W.; funding acquisition, Z.H. All authors have read and agreed to the published version of the manuscript.

Funding: This research was funded by (1) Jiangxi Social Science Planning Project, grant number (\#20DQ09); (2) Science and technology research project of Education Department of Jiangxi, grant number\#: GJJ190766.

Institutional Review Board Statement: Not applicable.

Informed Consent Statement: Informed consent was obtained from all subjects involved in the study.

Data Availability Statement: The data and models used during the study are available from the authors by request.

Conflicts of Interest: The authors declare no conflict of interest.

\section{References}

1. Clark, M.A.; Springmann, M.; Hill, J.; Tilman, D. Multiple health and environmental impacts of foods. Proc. Natl. Acad. Sci. USA 2019, 116, 23357-23362. [CrossRef]

2. Klemm, S. Sustainable Eating; Academy of Nutrition and Dietetics: Chicago, IL, USA, 2019. Available online: https://www. eatright.org/health/lifestyle/culture-and-traditions/sustainable-eating (accessed on 20 January 2021).

3. Food and Agriculture Organization. Sustainable Diets and Biodiversity. Rome (IT): Food and Agriculture Organization of the United Nations. 2012. Available online: http:/ / www.fao.org/docrep/016/i3004e/i3004e.pdf (accessed on 20 January 2021).

4. Zhao, Q.G.; Yin, X.B.; Sun, M.; Liu, Y.X.; Hou, F.F.; Zhang, N. Theoretical development and practice of functional agriculture from 2008 to 2018. Soil 2018, 50, 1061-1071.

5. Maeda-Yamamoto, M. Development of functional agricultural products and use of a new health claim system in Japan. Trends Food Sci. Technol. 2017, 69, 324-332. [CrossRef]

6. Rayman, M.P. The importance of selenium to human health. Lancet 2000, 356, 233-241. [CrossRef]

7. Li, N.; Gao, Z.D.; Luo, D.G.; Tang, X.; Chen, D.F.; Hu, Y.H. Selenium level in the environment and the population of Zhoukoudian area, Beijing, China. Sci. Total Environ. 2007, 381, 105-111. [CrossRef]

8. Gao, J.; Liu, Y.; Huang, Y.; Lin, Z.Q.; Bañuelos, G.S.; Lam, M.H.; Yin, X. Daily selenium intake in a moderate selenium deficiency area of Suzhou, China. Food Chem. 2011, 126, 1088-1093. [CrossRef]

9. Bhati, R.; Verma, H.V. Antecedents of customer brand advocacy: A meta-analysis of the empirical evidence. J. Res. Interact. Mark. 2020, 14, 153-172. [CrossRef]

10. Jayanti, R.K.; Burns, A.C. The antecedents of preventive health care behavior: An empirical study. J. Acad. Mark. Sci. 1998, 26, 6-15. [CrossRef]

11. Michaelidou, N.; Hassan, L.M. The role of health consciousness, food safety concern and ethical identity on attitudes and intentions towards organic food. Int. J. Consum. Stud. 2008, 32, 163-170. [CrossRef]

12. Schlarb, A.A.; Claßen, M.; Grünwald, J.; Vögele, C. Sleep disturbances and mental strain in university students: Results from an online survey in Luxembourg and Germany. Int. J. Ment. Health Syst. 2017, 11, 24. [CrossRef]

13. Lin, S. Relationship between Nutritional Labeling and Consumer Purchase Intention. Master's Thesis, Wenzao Ursuline University of Languages, Kaohsiung, Taiwan, 2014. 
14. Kim, K.Y.; Yim, M.Y.-C.; Kim, E.A.; Reeves, W. Exploring the optimized social advertising strategy that can generate consumer engagement with green messages on social media. J. Res. Interact. Mark. 2021, 15, 30-48. [CrossRef]

15. Enneking, U.; Neumann, C.; Henneberg, S. How important intrinsic and extrinsic product attributes affect purchase decision. Food Qual. Prefer. 2007, 18, 133-138. [CrossRef]

16. Bagust, A.; Hopkinson, P.K.; Maslove, L.; Currie, C.J. The projected health care burden of type 2 diabetes in the UK from 2000 to 2060. Diabet. Med. 2002, 19, 1-5. [CrossRef]

17. Prasad, A.; Strijnev, A.; Qin, Z. What can grocery basket data tell us about health consciousness? Int. J. Res. Mark. 2008, 25, 301-309. [CrossRef]

18. Choi, S.I.; Kwak, J.H. A Study on Effect of Silver Consumer's Lifestyle on Purchase Satisfaction and Repurchase Intention of the Health Functional Foods. Korean J. Food Nutr. 2007, 20, 334-340.

19. Wang, C.L.; Sarkar, J.G.; Sarkar, A. Hallowed be thy brand: Measuring perceived brand sacredness. Eur. J. Mark. 2019, 53, 733-757. [CrossRef]

20. Cuevas, L.; Lyu, J.; Lim, H. Flow matters: Antecedents and outcomes of flow experience in social search on Instagram. J. Res. Interact. Mark. 2021, 15, 49-67. [CrossRef]

21. Wang, C.L. New frontiers and future directions in interactive marketing: Inaugural Editorial. J. Res. Interact. Mark. 2021, 15, 1-9. [CrossRef]

22. Wang, C.L.; Jiang, Y. Examining consumer affective goal pursuit in services: When affect directly influences satisfaction and when it does not. Asia Pac. J. Mark. Logist. 2020, 32, 1177-1193. [CrossRef]

23. Bao, Z.; Wang, D. Examining consumer participation on brand microblogs in China: Perspectives from elaboration likelihood model, commitment-trust theory and social presence. J. Res. Interact. Mark. 2021, 15, 10-29. [CrossRef]

24. Vander Schee, B.A.; Peltier, J.; Dahl, A.J. Antecedent consumer factors, consequential branding outcomes and measures of online consumer engagement: Current research and future directions. J. Res. Interact. Mark. 2020, 14, 239-268. [CrossRef]

25. Handarkho, Y.D. The intentions to use social commerce from social, technology, and personal trait perspectives: Analysis of direct, indirect, and moderating effects. J. Res. Interact. Mark. 2020, 14, 305-336. [CrossRef]

26. Schwarzer, R. Psychology of Health Behavior, 3rd ed.; Hogrefe: Goettingen, Germany, 2004.

27. Han, Y. The Influence of Self-Control on Individual Food Reward Decision Making and Its Neural Mechanism. Master's Thesis, Southwest University, Chongqing, China, 2017.

28. Lazzarini, G.A.; Zimmermann, J.; Visschers, V.H.; Siegrist, M. Does environmental friendliness equal healthiness? Swiss consumers' perception of protein products. Appetite 2016, 105, 663-673. [CrossRef]

29. Buzby, J.C.; Ready, R.C.; Skees, J.R. Contingent valuation in food policy analysis: A case study of a pesticide-reside risk reduction. J. Agric. Appl. Econ. 1995, 27, 613-625. [CrossRef]

30. Steptoe, A.; Pollard, T.M.; Wardle, J. Development of a Measure of the Motives Underlying the Selection of Food: The Food Choice Questionnaire. Appetite 1995, 25, 267-284. [CrossRef]

31. Siegrist, M.; Hartmann, C. Perceived naturalness, disgust, trust and food neophobia as predictors of cultured meat acceptance in ten countries. Appetite 2020, 155, 104814. [CrossRef]

32. Hartmann, C.; Siegrist, M. Our daily meat: Justification, moral evaluation and willingness to substitute. Food Qual. Prefer. 2020, 80, 103799. [CrossRef]

33. Etale, A.; Siegrist, M. Food processing and perceived naturalness: Is it more natural or just more traditional? Food Qual. Prefer. 2021, 94, 104323. [CrossRef]

34. Bryant, C.; Szejda, K.; Parekh, N.; Desphande, V.; Tse, B. A survey of consumer perceptions of plant-based and clean meat in the USA, India, and China. Front. Sustain. Food Syst. 2019, 3, 11. [CrossRef]

35. Rozin, P. Naturalness Judgments by Lay Americans: Process Dominates Content in Judgments of Food or water Acceptability and Naturalness. Judgm. Decis. Mak. 2006, 1, 91-97.

36. Rozin, P.; Spranca, M.; Krieger, Z.; Neuhaus, R.; Surillo, D.; Swerdlin, A.; Wood, K. Natural Preference: Instrumental and Ideational/Moral Motivations, and the Contrast between Foods and Medicines. Appetite 2004, 43, 147-154. [CrossRef]

37. Siipi, H. Is Natural Food Healthy? J. Agric. Environ. Ethics 2013, 26, 797-812. [CrossRef]

38. Asioli, D.; Aschemann-Witzel, J.; Caputo, V.; Vecchio, R.; Annunziata, A.; Næs, T.; Varela, P. Making sense of the "clean label" trends: A review of consumer food choice behavior and discussion of industry implications. Food Res. Int. 2017, 99, 58-71. [CrossRef]

39. Soylemez, K.C. $4 \mathrm{~W}$ of user-generated content: Why who we are and where we post influence what we post. J. Res. Interact. Mark. 2021, 15, 386-400. [CrossRef]

40. Liu, B.B.; Qing, P.; Kuang, Y.T. Expensive and Fine or Inexpensive but Deserved: Consumers' Decision-Making for Biofortification Products. J. Huazhong Agric. Univ. 2019, 6, 60-69, 162.

41. You, S.Y.; Park, M.E. Consumer Preference for the Types of Labels of Cereal Products and Purchase Intention of Nutrition-labeled Products. Korean J. Community Living Sci. 2013, 24, 327-342. [CrossRef]

42. Drichoutis, A.C.; Lazaridis, P.; Nayga, R.M., Jr.; Kapsokefalou, M.; Chryssochoidis, G. A theoretical and empirical investigation of nutritional label use. Eur. J. Health Econ. 2008, 9, 293-304. [CrossRef]

43. Abbott, R. Food and nutrition information: A study of sources, uses, and understanding. Br. Food J. 1997, 99, 43-49. [CrossRef] 
44. Tang, C.H.; Zhao, Q.Y.; Zhang, K.; Li, S.; Qin, Y.C.; Zhang, J.M. Promoting the Development of Nutritionally-Guided Agriculture in Research and Development of Selenium-Enriched Agri-Products in China. Sci. Agric. Sin. 2019, 52, $3122-3133$.

45. Fu, L.F.; Deng, H.L.; Wei, W.; Xu, S.Y. Analysis of Influencing Factors and Consumption Behavior of Green Agricultural Products Based on Probit Model. Ecol. Econ. 2014, 30, 60-64.

46. Muda, M.; Hamzah, M.I. Should I suggest this YouTube clip? The impact of UGC source credibility on eWOM and purchase intention. J. Res. Interact. Mark. 2021, 15, 441-459. [CrossRef]

47. Chen, Y.Z.; Bai, Y.D.L.; Jia, L.G.; Gao, Y.J. Research significance and development and utilization status of selenium rich vegetables. North. Hortic. 2018, 18, 152-156.

48. Mai, R.; Hoffmann, S. Taste lovers versus nutrition fact seekers: How health consciousness and self-efficacy determine the way consumers choose food products. J. Consum. Behav. 2012, 11, 316-328. [CrossRef]

49. Huang, Z.; Wang, C.L. Conspicuous consumption in emerging market: The case of Chinese migrant workers. J. Bus. Res. 2018, 86, 366-373. [CrossRef]

50. Hayes, A.F. Introduction to mediation, moderation, and conditional process analysis: A regression-based approach. J. Educ. Meas. 2013, 51, 335-337.

51. Burlingame, B. Sustainable diets and biodiversity-Directions and solutions for policy research and action. In Proceedings of the International Scientific Symposium Biodiversity and Sustainable Diets United Against Hunger; FAO: Rome, Italy, 2012.

52. Meyer, N.L. Good food, health, and sustainability: An introduction for health professionals. Acsms Health Fit. J. 2015, 19, 12-21. [CrossRef]

53. Swan, E.L.; Dahl, A.J.; Peltier, J.W. Health-care marketing in an omni-channel environment: Exploring telemedicine and other digital touchpoints. J. Res. Interact. Mark. 2019, 13, 602-618. [CrossRef]

54. Izogo, E.E.; Mpinganjira, M. Behavioral consequences of customer inspiration: The role of social media inspirational content and cultural orientation. J. Res. Interact. Mark. 2020, 14, 431-459. [CrossRef]

55. Qin, Y.S. Fostering brand-consumer interactions in social media: The role of social media uses and gratifications. J. Res. Interact. Mark. 2020, 14, 337-354. [CrossRef]

56. Elsharnouby, M.H.; Mohsen, J.; Saeed, O.T.; Mahrous, A.A. Enhancing resilience to negative information in consumer-brand interaction: The mediating role of brand knowledge and involvement. J. Res. Interact. Mark. 2021, 15, 571-591. [CrossRef]

57. Raghunathan, R.; Naylor, R.W.; Hoyer, W.D. The unhealthy = tasty intuition and its effects on taste inferences, enjoyment, and choice of food products. J. Mark. 2006, 70, 170-184. [CrossRef]

58. Shen, Z. A persuasive eWOM model for increasing consumer engagement on social media: Evidence from Irish fashion micro-influencers. J. Res. Interact. Mark. 2021, 15, 181-199.

59. Vazquez, E.E. Effects of enduring involvement and perceived content vividness on digital engagement. J. Res. Interact. Mark. 2020, 14, 1-16. [CrossRef]

60. Ho, J.; Pang, C.; Choy, C. Content marketing capability building: A conceptual framework. J. Res. Interact. Mark. 2020, 14, $133-151$. [CrossRef]

61. Brinson, N.H.; Britt, B.C. Reactance and turbulence: Examining the cognitive and affective antecedents of ad blocking. J. Res. Interact. Mark. 2021, 15, 549-570. [CrossRef]

62. Hamzah, Z.L.; Wahab, H.A.; Waqas, M. Unveiling drivers and brand relationship implications of consumer engagement with social media brand posts. J. Res. Interact. Mark. 2021, 15, 336-358. [CrossRef]

63. Coker, K.K.; Flight, R.L.; Baima, D.M. Video storytelling ads vs argumentative ads: How hooking viewers enhances consumer engagement. J. Res. Interact. Mark. 2021, 15, 607-622. [CrossRef]

64. Kucharska, W. Online brand communities' contribution to digital business models: Social drivers and mediators. J. Res. Interact. Mark. 2019, 13, 437-463. [CrossRef]

65. Kaur, S.; Kumar, S. How sharenting drives sherub marketing: Insights from an interpretative phenomenological perspective. $J$. Res. Interact. Mark. 2021, 15, 750-768. [CrossRef]

66. Graham, K.W.; Wilder, K.M. Consumer-brand identity and online advertising message elaboration: Effect on attitudes, purchase intent and willingness to share. J. Res. Interact. Mark. 2020, 14, 111-132. [CrossRef]

67. Dessart, L.; Veloutsou, C. Augmenting brand community identification for inactive users: A uses and gratification perspective. J. Res. Interact. Mark. 2021, 15, 361-385. [CrossRef]

68. Lee, J.A.; Eastin, M.S. Perceived authenticity of social media influencers: Scale development and validation. J. Res. Interact. Mark. 2021, 15, 822-841. [CrossRef]

69. Zhou, L.; Xue, F. Show products or show people: An eye-tracking study of visual branding strategy on Instagram. J. Res. Interact. Mark. 2021, 15, 729-749. [CrossRef]

70. Vashisht, D. The effect of novelty in in-game advertising: Examining the moderating role of interactivity and congruency. J. Res. Interact. Mark. 2021, 15, 769-786. [CrossRef]

71. National Institute of Health. Available online: https:/ / ods.od.nih.gov/factsheets/Selenium-HealthProfessional/ (accessed on 20 January 2021).

72. Nunnally, J.C.; Bernstein, I.H. The Assessment of Reliability. Psychom. Theory 1994, 3, 248-292. 